\title{
Profil penyakit kulit pada pelajar sekolah asrama di Kabupaten Magelang, Jawa Tengah
}

\author{
Tuntas Rayinda, Devi Artami Susetiati,* Sri Awalia Febriana \\ Departemen Dermatologi dan Venereologi, Fakultas Kedokteran, Kesehatan Masyarakat, dan \\ Keperawatan, Universitas Gadjah Mada, Yogyakarta, Indonesia
}

\section{Submitted: 25 Agustus 2018 Revised: 30 Oktober 2018 Accepted: 16 November 2018}

\begin{abstract}
ABSTRAK Individu di sekolah asrama sering mengalami berbagai penyakit kulit, baik infeksi maupun noninfeksi, karena paparan bermacam faktor risiko seperti perubahan hormonal, higienitas dan sanitasi yang buruk, dan tempat tinggal yang padat. Sampai saat ini data mengenai prevalensi penyakit pada remaja di sekolah asrama masih sangat terbatas. Penelitian ini merupakan penelitian observasional dengan desain potong lintang yang bertujuan untuk mendeskripsikan penyakit kulit yang sering terjadi pada remaja yang tinggal di sekolah asrama. Survei dan pemeriksaan klinis dilakukan oleh dokter spesialis kulit dan kelamin. Berdasarkan survei yang dilakukan pada 1.250 pelajar berusia 10 - 16 tahun di dua asrama di Kabupaten Magelang, sebanyak 1.073 pelajar $(85,8 \%)$ memiliki setidaknya satu penyakit kulit. Sebanyak 1.073 kasus dari 27 jenis penyakit kulit yang berbeda ditemukan pada para pelajar tersebut. Lima penyakit kulit yang paling banyak ditemui adalah dermatofitosis, skabies, akne vulgaris, ektima, dan pitiriasis versicolor. Edukasi, survei secara periodik, pengobatan secara massal, dan intervensi untuk meningkatkan higienitas dan kondisi tempat tinggal merupakan kunci keberhasilan dalam manajemen penyakit kulit pada pelajar yang tinggal di asrama.
\end{abstract}

KATA KUNCI penyakit kulit; asrama; dermatofitosis; scabies; akne vulgaris

ABSTRACT Individuals who live in boarding schools often experience various skin diseases, both infection and non-infectious because of exposure to various risk factors such as hormonal changes, poor hygiene and sanitation, and dense living quarters. To date, data on the prevalence of disease in adolescents in boarding schools are still very limited. This study is an observational cross-sectional study that aims to describe skin diseases that often occur in adolescents who live in boarding schools. Surveys and clinical examinations are carried out by dermatologist. Based on a survey of 1,250 students aged $10-16$ years, 1,073 students (85.8\%) had at least one skin disease. A total of 1,073 cases from 27 different types of skin diseases were found in these students. The five most common skin diseases are dermatophytosis, scabies, acne vulgaris, ecthyma, and pityriasis versicolor. Education, periodic surveys, mass treatment, and interventions to improve hygiene and living conditions are key to success in the management of skin diseases in students living in boarding schools.

KEYWORDS skin disease; boarding school; dermatophytosis; scabies; acne vulgaris

\footnotetext{
*Corresponding author: Devi Artami Susetiati

Departemen Dermatologi dan Venereologi, Fakultas Kedokteran, Kesehatan Masyarakat, dan Keperawatan, Universitas Gadjah Mada, Jl. Farmako, Sekip Utara, Yogyakarta 55281, Indonesia

E-mail: dephieart@yahoo.com
} 


\section{Pendahuluan}

Remaja yang tinggal di sekolah asrama sering mengalami berbagai penyakit kulit, baik infeksi maupun non-infeksi. ${ }^{1}$ Berbagai faktor risiko, seperti perubahan hormonal, higienitas, dan tempat tinggal yang padat dapat menjadi faktor risiko kejadian penyakit-penyakit kulit pada remaja yang tinggal di sekolah asrama. ${ }^{2,3}$

Penyakit kulit pada remaja sering tidak dihiraukan. Kurangnya perhatian dari guru atau pengasuh sering menyebabkan penyakit-penyakit kulit tersebut tidak terdeteksi dan mengalami keterlambatan dalam pengobatan. ${ }^{4} \mathrm{Hal}$ tersebut berakibat pada peningkatan morbiditas penyakit kulit yang dialami para remaja. Saat ini, data mengenai prevalensi penyakit pada remaja di sekolah asrama masih sangat terbatas. Kami melakukan survei pada 1.250 pelajar yang tinggal di dua sekolah asrama di Kabupaten Magelang, Jawa Tengah dengan rentang usia 10 - 16 tahun.

Tujuan penelitian ini adalah untuk mengetahui prevalensi penyakit kulit yang sering terjadi pada remaja yang bersekolah dan tinggal di sekolah asrama. Dengan data prevalensi yang baik, prevensi maupun intervensi dapat dilakukan sedini mungkin, sehingga permasalahan kulit pada remaja yang tinggal di sekolah asrama jumlahnya dapat diturunkan dan dapat ditangani dengan baik.

\section{Metode}

Penelitian ini merupakan penelitian potong lintang retrospektif menggunakan data sekunder yang diperoleh dari kegiatan pengabdian masyarakat yang dilakukan di dua sekolah asrama berlatar belakang agama di Kabupaten Magelang, Provinsi Jawa Tengah, tahun 2016 - 2017. Pemilihan sekolah dilakukan dengan menggunakan metode nonprobability sampling. Kriteria inklusi subjek adalah remaja berusia 10 - 24 tahun yang tinggal di sekolah asrama yang dipilih.

Pada penelitian ini dilakukan survei terhadap 1.250 pelajar. Sebelum dilakukan pemeriksaan, pelajar diberikan penyuluhan mengenai tanda dan gejala penyakit-penyakit kulit yang sering terjadi pada remaja. Pelajar yang mengalami keluhan kemudian diperiksa fisik secara menyeluruh. Pemeriksaan dan penegakan diagnosis dilakukan oleh dokter spesialis kulit dan kelamin berdasarkan kriteria klinis. Setelah diagnosis ditegakkan, para pelajar mendapatkan pengobatan sesuai terapi standar penyakit atau dirujuk ke fasilitas kesehatan terdekat. Selain data mengenai diagnosis penyakit, data demografis seperti usia, jenis kelamin, juga dilaporkan. Gambar 1 menunjukkan proses penelitian.

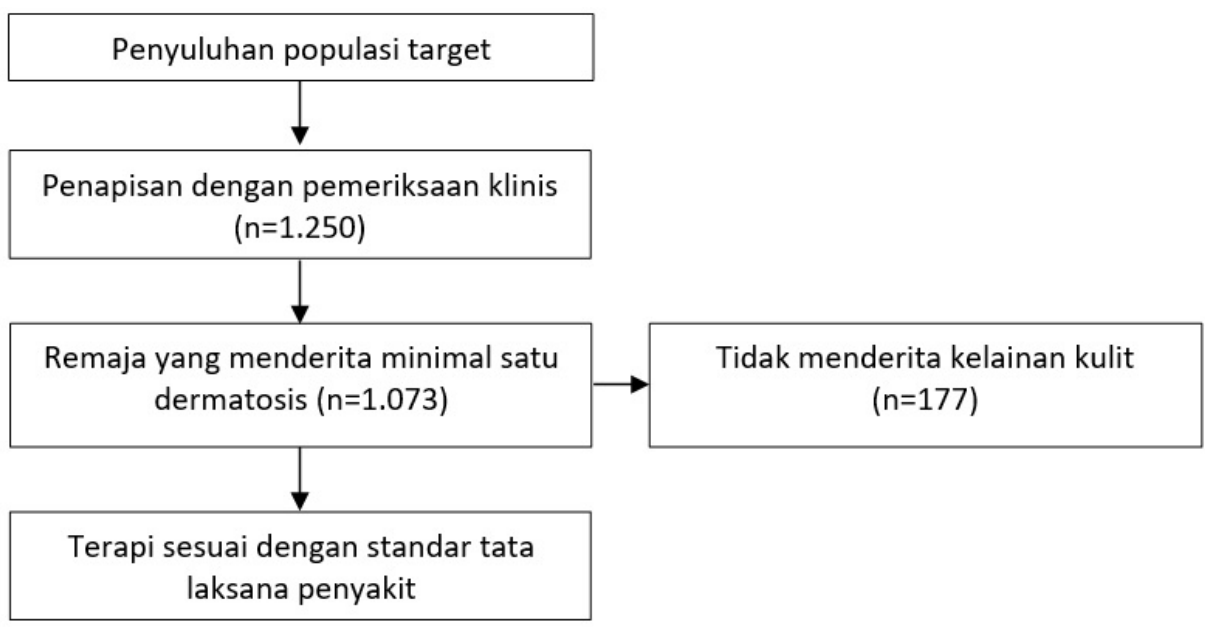

Gambar 1. Alur penelitian pada remaja di dua sekolah asrama di Magelang 


\section{Hasil}

Pada penelitian ini dilakukan survei terhadap 1.250 pelajar yang tinggal di dua sekolah asrama di Kabupaten Magelang, Jawa Tengah, dengan rentang usia 10 - 16 tahun. Sebanyak 735 (58,8\%) pelajar berjenis kelamin laki-laki dan sebanyak 515 (42,2\%) pelajar berjenis kelamin perempuan. Mayoritas subjek memiliki tingkat sosial ekonomi menengah ke bawah dan sedang menempuh pendidikan dari SD hingga SMA. Kedua asrama yang dipilih berlatar belakang agama dengan daerah sekitar memiliki banyak komunitas santri atau sekolah agama. Kapasitas setiap kamar di asrama adalah 40 anak, dengan ukuran kamar seluas sekitar $6 \times 5 \mathrm{~m}^{2}$

Sebanyak 1.073 pelajar (85,8\%) memiliki setidaknya satu keluhan kulit. Berdasarkan pemeriksaan klinis, terdapat 27 jenis penyakit kulit yang berbeda yang ditemukan pada para pelajar tersebut. Lima penyakit kulit yang paling banyak ditemui adalah dermatofitosis $(37,74 \%)$, skabies $(35,78 \%)$, akne vulgaris $(15,84 \%)$, ektima $(3,26 \%)$, serta pitiriasis versicolor dan dermatitis kontak iritan (masing-masing 0,74\%). Rincian dermatosis yang paling banyak ditemui dalam penelitian ini dapat dilihat pada Tabel 1.

\section{Pembahasan}

Berbagai penyakit kulit, baik infeksi maupun non infeksi, sering terjadi pada remaja dengan prevalensi berkisar 58,3\% hingga $72,1 \%$ di Nigeria. ${ }^{5}$ Pada penelitian ini, angka prevalensi penyakit kulit yang ditemukan pada remaja sekolah asrama lebih tinggi, yaitu $85,8 \%$.

Penyakit kulit pada remaja, terutama akne, memiliki dampak negatif dan dapat mempengaruhi kualitas hidup remaja. ${ }^{6}$ Lebih dari itu, akne yang terjadi pada remaja juga dapat menyebabkan rasa malu, depresi, bahkan keinginan untuk bunuh diri. ${ }^{7}$ Penyakit kulit lain misalnya skabies, dermatofitosis, dan infeksi bakteri superfisial, selain dapat menyebabkan rasa gatal yang mengganggu aktivitas sehari-hari maupun jam istirahat para remaja, kondisi tersebut juga dapat menyebabkan rasa malu karena penampilan kulit yang buruk. ${ }^{8}$
Tabel 1. Penyakit kulit yang ditemui pada remaja yang tinggal di dua sekolah asrama di Magelang

\begin{tabular}{lcc}
\hline \multicolumn{1}{c}{ Diagnosis } & $\mathbf{n}$ & $\mathbf{\%}$ \\
\hline Dermatofitosis & 405 & 37,74 \\
Skabies & 384 & 35,78 \\
Akne vulgaris & 170 & 15,84 \\
Ektima & 35 & 3,26 \\
Pitiriasis versicolor & 8 & 0,74 \\
Dermatitis kontak iritan & 8 & 0,74 \\
Dermatitis seboroik & 7 & 0,65 \\
Hiperpigmentasi paska inflamasi & 7 & 0,65 \\
Papul urtikaria & 6 & 0,56 \\
Dermatitis kontak alergi & 5 & 0,47 \\
Prurigo simpleks & 5 & 0,47 \\
Dermatitis atopik & 4 & 0,37 \\
Keratosis pilaris & 4 & 0,37 \\
Liken simpleks kronis & 4 & 0,37 \\
Dermatitis numular & 2 & 0,19 \\
Ketombe & 2 & 0,19 \\
Dermatitis fotokontak alergi & 2 & 0,19 \\
Keloid & 2 & 0,19 \\
Keratoderma & 2 & 0,19 \\
Pruritus & 2 & 0,19 \\
Folikulitis & 2 & 0,19 \\
Candidiasis & 1 & 0,09 \\
Dermatitis intertrigo & 2 & 0,19 \\
Furunkel & 1 & 0,09 \\
Insect bite & 1 & 0,09 \\
Liken nitidus & 1 & 0,09 \\
Morbus hansen & 1 & 0,09 \\
\hline
\end{tabular}

Remaja di negara berkembang lebih berisiko mengalami kelainan kulit. Kondisi lingkungan yang lembap dan panas, serta kondisi sosial, seperti higienitas yang rendah akan meningkatkan risiko terjadinya kelainan kulit pada remaja. Risiko terjadinya transmisi silang penyakit infeksi kulit pada remaja lebih tinggi di sekolah asrama karena seringnya kontak antar siswa. ${ }^{9}$ Pada penelitian ini dilakukan survei pada remaja yang bersekolah dan tinggal di sekolah asrama. Para remaja tersebut mempunyai aktivitas sehari-hari yang tinggi sehingga mereka juga berisiko mengalami trauma lebih tinggi. Hal tersebut meningkatkan kemungkinan penularan antar individu. ${ }^{1}$ 
Penyakit kulit yang paling banyak ditemui adalah dermatofitosis (37,74\%). Hal tersebut sesuai dengan penelitian serupa yang dilakukan di Turki pada 682 pelajar laki-laki yang tinggal di asrama. Pada penelitian tersebut, tinea pedis dan onikomikosis merupakan penyakit yang paling banyak ditemui, masing-masing dengan prevalensi $32,5 \%$ dan $8,04 \% .{ }^{1}$ Penelitian lain yang melakukan survei penyakit kulit dan higienitas di sebuah sekolah di daerah rural di India juga melaporkan bahwa dermatofitosis merupakan salah satu dari lima penyakit terbanyak yang ditemui. ${ }^{2}$ Tingginya kejadian dermatofitosis tersebut dapat disebabkan karena banyaknya faktor risiko di sekolah asrama, seperti higienitas yang buruk dan kontak dengan individu yang menderita dermatofitosis. Menurut sebuah penelitian di daerah rural di Turki, variabel independen yang berkaitan dengan meningkatnya risiko kejadian dermatofitosis adalah usia tua, lakilaki, higienitas dan sanitasi yang buruk, tinggal di asrama, edukasi ibu yang rendah, dan riwayat dermatofitosis dalam keluarga. ${ }^{10}$

Pada penelitian ini, skabies merupakan penyakit kedua yang paling banyak dijumpai $(35,78 \%)$. Temuan ini serupa dengan penelitianpenelitian yang dilakukan pada remaja usia sekolah di Nigeria dan India., ${ }^{2,11}$ Angka kejadian skabies yang tinggi banyak dilaporkan pada tempat tinggal maupun rumah tinggal yang padat penduduk. ${ }^{12}$ Hal ini berkaitan dengan transmisi skabies yang dapat terjadi melalui kontak kulit dengan kulit atau melalui pakaian ke kulit. ${ }^{13,14}$

Selain dermatofitosis dan skabies, penyakit infeksi lain yang banyak ditemukan pada penelitian ini adalah ektima $(3,26 \%)$ dan pitiriasis versicolor $(0,74 \%)$. Ektima merupakan bentuk infeksi bakteri superfisial yang insidensinya naik pada lingkungan dengan higienitas yang buruk. ${ }^{15}$ Kejadian skabies yang tinggi juga merupakan faktor risiko terjadinya infeksi bakteri superfisial di kulit karena siklus gatal - garuk yang berlangsung terus menerus dan merusak fungsi sawar kulit. ${ }^{12,16}$ Pitiriasis versicolor disebabkan oleh infeksi Malassezia sp. pada stratum korneum dan banyak terjadi pada individu berusia remaja di negara beriklim tropis maupun subtropis.
Kejadian pitiriasis versicolor juga dikaitkan dengan higienitas yang buruk. ${ }^{17}$

Akne vulgaris, seperti yang ditemukan pada penelitian ini, merupakan penyakit inflamasi kronis pada unit pilosebasea yang banyak terjadi pada remaja. ${ }^{18}$ Pada penelitian ini, akne vulgaris ditemukan pada $15,84 \%$ remaja yang tinggal di asrama. Angka ini lebih rendah daripada temuan pada laporan terdahulu mengenai kejadian akne pada pelajar di asrama. ${ }^{1}$ Tingginya kejadian akne pada remaja disebabkan karena peran hormonal dalam patogenesis akne. Peningkatan hormon pertumbuhan pada remaja yang memicu peningkatan kadar hormon androgen pada remaja berkorelasi dengan terbentuknya akne yang berat. ${ }^{19}$ Kejadian akne juga erat hubungannya dengan indeks massa tubuh serta onset pubertas. Hal-hal tersebut menjadikan akne sebagai salah satu dermatosis kronis yang banyak ditemui di usia remaja. ${ }^{20}$

Dengan melihat tingginya kejadian penyakit kulit pada remaja yang tinggal di dalam sekolah asrama, diperlukan kebijakan khusus untuk penanganan kasus-kasus tersebut. Identifikasi dan pengobatan secara berkala terhadap semua pelajar di suatu sekolah asrama yang dilakukan oleh tenaga medis merupakan hal penting yang harus dilakukan untuk mengendalikan morbiditas penyakit kulit. Untuk penyakit kulit yang ditularkan, misalnya skabies dan dermatofitosis, edukasi dan pengobatan secara massal merupakan kunci dalam tata laksana kasus-kasus tersebut. Kegiatan tersebut perlu dijadikan program kesehatan di sekolah asrama. ${ }^{21}$ Edukasi kepada guru dan pamong juga perlu dilakukan agar deteksi kasus dapat dilakukan lebih dini. ${ }^{22}$

Penelitian ini merupakan penelitian dengan desain potong lintang sehingga tidak memungkinkan untuk melihat sebab akibat. Berbagai variabel klinis yang dapat memengaruhi kejadian dermatosis pada remaja juga tidak dinilai dalam penelitian ini. Diagnosis yang ditegakkan oleh lebih dari satu dokter spesialis kulit dan kelamin juga merupakan keterbatasan lain dari penelitian ini. 


\section{Kesimpulan}

Penyakit infeksi, baik yang disebabkan oleh parasit, dermatofita, maupun bakteri merupakan penyakit yang paling banyak ditemui pada remaja yang tinggal di sekolah asrama. Higienitas dan tempat tingggal yang dihuni oleh banyak orang merupakan faktor risiko utama terjadinya penyakit infeksi tersebut. Edukasi, penapisan penyakit kulit secara periodik, pengobatan secara massal, dan intervensi untuk meningkatan higienitas dan kondisi tempat tinggal merupakan kunci keberhasilan dalam manajemen penyakit - penyakit tersebut

\section{Ucapan terima kasih}

Terima kasih kami ucapkan kepada seluruh pihak di sekolah asrama yang membantu dalam terlaksananya kegiatan pengabdian kepada masyarakat sekaligus penelitian ini. Ucapan terima kasih juga kami ucapkan kepada Perhimpunan Dokter Spesialis Kulit dan Kelamin Indonesia (Perdoski) Cabang Yogyakarta yang telah memberikan dana hibah sehingga kegiatan ini dapat terlaksana.

\section{Daftar pustaka}

1. Tuncel AA, Erbagci Z. Prevalence of skin diseases among male adolescent and postadolescent boarding school students in Turkey. J Dermatol. 2005;32(7):557-64.

2. Wasnik $S$, Pinto $V$, Joshi S. Prevalence of skin infections and regular personal hygiene practices in ashram school students: A crosssectional study. Natl J Community Med. 2018;9(4):274-7.

3. Di Landro A, Cazzaniga S, Parazzini F, Ingordo V, Cusano F, Atzori L, et al. Family history, body mass index, selected dietary factors, menstrual history, and risk of moderate to severe acne in adolescents and young adults. J Am Acad Dermatol. 2012;67(6):1129-35.

4. Hossenbaccus Z, Jeewon R. Skin infections among infants and parental awareness: Is there any relationship? Our Dermatology Online. 2014;5(4):353-8.
5. Henshaw EB, Olasode OA, Ogedegbe EE, Etuk I. Dermatologic conditions in teenage adolescents in Nigeria. Adolesc Health Med Ther. 2014;5:79-87.

6. K Dunn L, L O'Neill J, R Feldman S. Acne in adolescents: Quality of life, self-esteem, mood, and psychological disorders. Dermatol Online J. 2011;17(1):1.

7. Hull PR, D'Arcy C. Acne, depression, and suicide. Dermatol Clin. 2005;23(4):665-74.

8. Golics CJ, Basra MKA, Finlay AY, Salek MS. Adolescents with skin disease have specific quality of life issues. Dermatology. 2009;218(4):357-66.

9. Khatami A, San Sebastian M. Skin disease: A neglected public health problem. Dermatol Clin. 2009;27(2):99-101.

10. Metintas S, Kiraz N, Arslantas D, Akgun $\mathrm{Y}$, Kalyoncu $C$, Kiremitçi $A$, et al. Frequency and risk factors of dermatophytosis in students living in rural areas in Eski, Sehir, Turkey. Mycopathologia. 2004;157:379-82.

11. Ogunbiyi AO, Owoaje E, Ndahi A. Prevalence of skin disorders in school children in Ibadan, Nigeria. Pediatr Dermatol. 2005;22(1):6-10.

12. Chosidow O, Ph D. Scabies. N Engl J Med. 2006;354(16):1718-27.

13. Johnston $G$, Sladden $M$, Royal L. Scabies: Diagnosis and treatment. $\mathrm{Br}$ Med J. 2005;331(September):619-22.

14. Wang C-H, Lee S-C, Huang S-S, Kao Y-C, See L-C, Yang S-H. Risk factors for scabies in Taiwan. $J$ Microbiol Immunol Infect. 2012;45(4):276-80.

15. Larson E. Skin hygiene and infection prevention: More of the same or different approaches? Clin Infect Dis. 1999;29(5):1287-94.

16. Romani L, Koroivueta J, Steer AC, Kama $M$, Kaldor JM, Wand $H$, et al. Scabies and impetigo prevalence and risk factors in Fiji : A national survey. PLOS Neglected Trop Dis. 2015;9(3):e0003452.

17. Salahi-moghaddam A, Davoodian $P$, Jafari $A$, Nikoo MA. Evaluation of pitiriasis versicolor in prisoners : A cross-sectional study. Indian J 
Dermatol Venereol Leprol. 2009;75(4):379-82.

18. Okoro E, Ogunbiyi A, George A. Prevalence and pattern of acne vulgaris among adolescents in Ibadan, south-west Nigeria. J Egypt Women's Dermatologic Soc. 2016;13:7-12.

19. Elsaie ML. Hormonal treatment of acne vulgaris: An update. Clin Cosmet Investig Dermatol. 2016;9:241-8.

20. Lynn DD, Umari T, Dunnick CA, Dellavalle RP. The epidemiology of acne vulgaris in late adolescence. Adolesc Health Med Ther.
2016;7:13-25.

21. Salavastru CM, Chosidow O, Boffa MJ, Janier M, Tiplica GS. European guideline for the management of scabies. Eur Guidel Manag scabies. 2017;31(8):1248-53.

22. Paredes SS, Estrada R, Alarcon $H$, Chavez G, Romero M, Hay R. Can school teachers improve the management and prevention of skin disease? A pilot study based on head louse infestations in Guerrero, Mexico. Int J Dermatol. 2008;36(11):826-30. 